\title{
Effects of dietary antioxidants on the quality, fatty acid profile, and lipid oxidation of longissimus muscle in Kacang goat with aging time.
}

\begin{abstract}
Thirty-two male goats were randomly assigned to four dietary treatments namely, basal diet $70 \%$ concentrate and $30 \%$ oil palm fronds (control, $\mathrm{CN}$ ), $\mathrm{CN}+400 \mathrm{mg} / \mathrm{kg}$ vitamin $\mathrm{E}$ (VE), $0.5 \%$ turmeric (TU) or $0.5 \%$ Anderographis paniculata (AP). After 100 days of feeding, the goats were slaughtered and longissimus dorsi (LD) muscle was sampled. The muscle was vacuum-packaged and conditioned for 0,7 and 14 days in a chiller $\left(4{ }^{\circ} \mathrm{C}\right)$. The drip loss of the LD muscle increased $(\mathrm{P}<0.05)$ with aging time. Meat tenderness was improved $(\mathrm{p}<0.05)$ at 14 days aging. All antioxidant supplements improved $(\mathrm{P}<0.05)$ colour of the meat. The TBARS value increased $(\mathrm{P}<0.05)$ at 7 days of aging while the fatty acid composition was not affected by the dietary supplements. It is concluded that TU and AP are potential dietary antioxidant supplements, for the purpose of improving the quality of chevon.
\end{abstract}

Keyword: Goat meat quality; Antioxidants; Andrographis paniculata; Turmeric; Vitamin E. 